\title{
Guía de medidas cautelares en el arbitraje comercial internacional con sede en Colombia
}

DOI: http://dx.doi.org/10.15425/2017.510

\section{Resumen}

Este artículo es una guía de entendimiento de las medidas cautelares y su análisis en el sistema colombiano en lo referente al arbitraje comercial internacional. Su importancia radica en que actualmente en Colombia no existe mucha investigación e indagación respecto de las medidas cautelares en el arbitraje comercial internacional con sede en Colombia, por lo cual busca que el lector tenga un mayor entendimiento de cómo se desarrollan y cómo se deberían desarrollar en la Ley 1563 del 2012, teniendo en cuenta que en otras jurisdicciones este concepto sí ha sido ampliamente estudiado y analizado.

\section{Palabras claves}

Medidas cautelares, autoridad judicial, tribunal arbitral, orden preliminar, árbitro de emergencia. 


\title{
Guide of precautionary measures in international commercial arbitration seated in Colombia
}

\begin{abstract}
This work is a guide for understanding precautionary measures and their analysis in the Colombian system in relation to international commercial arbitration. Its importance lies in the fact that currently in Colombia there is not much investigation regarding precautionary measures in international commercial arbitration seated in Colombia, it seeks that the reader has a greater understanding of how precautionary measures are developed and how they should be developed in Law 1563 of 2012, taking into account that in other jurisdictions this concept has been widely expressed and analyzed.
\end{abstract}

\section{Keywords}

Precautionary measures, judicial authority, arbitral tribunal, preliminary order, emergency arbitrator. 


\section{Introducción}

El objetivo principal de esta Guía de medidas cautelares en el arbitraje comercial internacional con sede en Colombia es explicar, con base en la jurisprudencia y doctrina internacional, la implementación de las distintas medidas cautelares en el sistema colombiano, al igual que analizar la relación existente entre el árbitro y el juez como autoridad judicial competente para decretar y ejecutar las medidas cautelares, así como hacer alusión a mecanismos como el árbitro de emergencia y la facultad que podría tener de decretar y ejecutar medidas cautelares bajo los distintos reglamentos internacionales de las respectivas instituciones arbitrales.

Esta guía no busca hacer un análisis del derecho comparado. Tampoco busca explicar si un arbitraje es o no de carácter comercial internacional, toda vez que en ningún momento pretende analizar situaciones a nivel nacional o respecto del arbitraje comercial nacional, ya que está enfocado en el arbitraje comercial internacional, a pesar de utilizar como sede a Colombia.

La presente guía utiliza una metodología en la que se acude, en primer lugar, a dar una definición de todos los conceptos básicos en relación con las medidas cautelares traídas en la Ley Modelo de la Comisión de las Naciones Unidas para el Derecho Mercantil Internacional -de ahora en adelante Ley Modelo y Uncitral, por su sigla en inglés-y en la Ley 1563 del 2012 como Estatuto Arbitral en Colombia, al igual que la explicación y análisis por parte del Grupo de Trabajo de la Uncitral en la redacción de la Ley Modelo. Se introducen múltiples casos que han sido relevantes en el arbitraje comercial internacional para hablar de los distintos tipos de medidas cautelares, al igual que figuras como el árbitro de emergencia. Así mismo, se hacen diversas comparaciones y análisis entre figuras relevantes en el arbitraje como el árbitro de emergencia, la autoridad judicial y el tribunal arbitral en relación con las medidas cautelares.

Esta guía cuenta con siete capítulos explicativos: el primero estudiará la medida cautelar en la Ley 1563 del 2012, su definición, las condiciones para el decreto y su diferencia con la Ley Modelo; el segundo capítulo explicará la orden preliminar vista desde la perspectiva de la Ley Modelo y la Ley 1563 del 2012; el tercer capítulo expresará los distintos tipos de medidas cautelares, es decir, las medidas anticipadas, nominadas, innominadas, injunction y anti suit injunctions; el cuarto capítulo analizará el decreto y práctica de las medidas cautelares por parte de los árbitros y la autoridad judicial; el quinto capítulo explicará la intervención del 
árbitro de emergencia con la medida cautelar; seguido a ese, los capítulos sexto y séptimo harán alusión al reconocimiento, ejecución y causales de denegación de la medida cautelar.

\section{Medidas cautelares en la Ley 1563 del 2012}

La Ley Modelo con la reforma del 2006 fue el gran parámetro para la adopción de la Ley 1563 del 2012 en lo referente a las medidas cautelares. La Ley 1563 del 2012 retoma el artículo 17 de la Ley Modelo que establece la posibilidad de que los tribunales arbitrales adopten medidas cautelares, salvo estipulación en contrario de las partes. En ambas leyes, la medida cautelar se entiende como "toda medida temporal, decretada en forma o no de laudo, por la que, en cualquier momento previo a la emisión del laudo por el que se dirima definitivamente la controversia, el tribunal arbitral ordene...", la cual busca mantener o restablecer el statu quo, o ejercer las acciones necesarias para prevenir un daño en el proceso arbitral, e incluso evitar un posible daño en la controversia.

Además, las medidas cautelares en el arbitraje internacional son órdenes que se solicitan ante un tribunal arbitral o autoridad judicial cuyo propósito es proteger a la parte para que las pruebas no se pierdan en el procedimiento arbitral y se pueda ejecutar el laudo futuro, además de preservar una situación legal y salvaguardar derechos cuyo reconocimiento se solicita al tribunal arbitral en cuanto al fondo de la controversia ${ }^{1}$.

La Gaceta 270 del 2012 del Congreso de la República en la cual se promulgó la Ley 1563 del 2012, en los debates de ponencia los congresistas establecieron que era necesario incluir las medidas cautelares en la nueva normatividad, para que de esta manera los arbitrajes "no se queden como saludos a la bandera, simplemente como un mecanismo eunuco" 2 .

En la práctica del arbitraje comercial internacional, estas medidas cautelares están dirigidas a mantener el statu quo; tomar acción para evitar un daño; preservar los bienes; preservar la evidencia o la propiedad; prevenir que la disputa

1 Gary B. Born, "Provisional measures in international arbitration", en International arbitration: Law and practice. (Países Bajos: Kluwer Law International, 2015), 209-226.

$2 \quad$ Ley 1563 del 2012. Gaceta 270 del 2012 del Congreso de la República. Comisión Primera Constitucional. Acta 33 del 2012. Bogotá, jueves, 24 de mayo del 2012. 
se agrave; cumplir con las obligaciones contractuales; y proporcionar seguridad en las reclamaciones ${ }^{3}$.

\section{A) Diferencia entre la definición de medida cautelar en la Ley Modelo y en la Ley 1563 del 2012}

Para comenzar, el artículo 80 de la Ley 1563 del 2012, tomado de lo establecido en el artículo 17 de la Ley Modelo, establece la facultad que tiene el tribunal arbitral para decretar medidas cautelares. Ambas leyes estipulan que el tribunal arbitral podrá otorgar medidas cautelares salvo acuerdo en contrario; también, la medida puede ser entendida como temporal, la cual puede ser decretada en cualquier momento previo a la emisión del laudo final. Dentro de los objetivos ambas leyes buscan: mantener o restablecer el statu quo de lo que se espera dirimir; adoptar medidas que impidan algún daño actual o inminente, o el menoscabo del procedimiento arbitral; proporcionar algún medio para preservar bienes que permitan ejecutar todo laudo, y preservar elementos de prueba que puedan ser relevantes y pertinentes en la controversia. En relación con lo mencionado, la definición y el objetivo de la medida cautelar tanto en la Ley Modelo como en la Ley 1563 del 2012 es exactamente igual ${ }^{4}$.

Ahora bien, en relación con las condiciones para el otorgamiento de las medidas cautelares, la Ley Modelo y la Ley 1563 del 2012 no establecen los mismos requisitos. Por un lado, el artículo 17A de la Ley Modelo señala que el solicitante de una medida cautelar deberá convencer al tribunal arbitral que, de no otorgarse la medida cautelar, es probable que se produzca un daño, no resarcible mediante indemnización, en el que dicho daño deberá ser notablemente más grave que el que pueda sufrir la parte afectada por la medida. Por otro lado, la disposición del artículo 81 de la Ley 1563 del 2012 establece que el solicitante de una medida debe demostrar la conducencia, pertinencia, razonabilidad y oportunidad de esta. Sin embargo, ambas leyes señalan que decretar una medida cautelar en ningún momento generará prejuzgamiento sobre la decisión del fondo de la controversia en la decisión del tribunal.

En este sentido, las condiciones para el otorgamiento de la medida cautelar no fueron replicadas ni adoptadas por Colombia de acuerdo con los lineamientos de la Ley Modelo, ya que la Ley 1563 del 2012 busca que para decretar la medida 
cautelar, esta se ciña al asunto de la controversia, esté relacionada con los hechos del caso, sea idónea para preservar el derecho del solicitante y necesaria.

En síntesis, la ley colombiana en lo que corresponde a las medidas cautelares no exige una demostración de la apariencia de buen derecho ni tampoco solicita que se exprese una probabilidad de ocurrencia del daño que, en caso de no concederse, no pueda ser resarcible adecuadamente por medio de una indemnización económica; por lo contrario, la Ley Modelo sí solicita acreditar que de no decretarse la medida cautelar se generaría un posible daño y señalar que dicho daño podría ser más grave que la medida previamente emitida, la cual no podrá ser resarcible por medio de indemnización. Además, la Ley 1563 del 2012 ni la Ley Modelo señalan qué se debe hacer con el otorgamiento de la medida en caso de la existencia de un árbitro de emergencia y su relación con el laudo final.

\section{Análisis de la orden preliminar}

La noción de la orden preliminar es un concepto nuevo que no se tenía en la Ley Modelo de 1985, sin embargo, la Uncitral, a través del Grupo de Trabajo, por medio de las revisiones de la Ley Modelo en el año 2006, trajo a colación este precepto. La orden preliminar busca ser un mecanismo para que se tenga una mayor velocidad en el arbitraje, en el que una parte podrá presentar una solicitud de la medida cautelar junto con una solicitud de orden preliminar con el objetivo de que no se frustre el propósito de la medida cautelar requerida ${ }^{5}$.

Es menester señalar que las medidas cautelares son diferentes a las órdenes preliminares, teniendo en cuenta que las primeras buscan ser un medio para preservar el statu quo y garantizar la efectividad de la decisión hasta el momento en que el tribunal arbitral emita la decisión final; mientras que las órdenes preliminares también buscan asegurar el statu quo pero de la medida cautelar. Es decir que la orden preliminar está dirigida a prevenir que se produzca un riesgo que frustre la medida cautelar solicitada.

Las condiciones para conceder las órdenes preliminares corresponden a las mismas que se tienen para la concesión de las medidas cautelares, no obstante, se adiciona que es una solicitud en la que una de las partes justifica su necesidad ante 
el tribunal arbitral basada en que, de no otorgarse, se corre el riesgo de frustrar la medida cautelar ${ }^{6}$.

En tratándose de órdenes preliminares, ambas leyes otorgan el derecho de contradicción, en la que se le da la posibilidad a la parte contra la cual va dirigida la orden preliminar de defenderse y hacer valer sus derechos en la mayor brevedad posible, sin establecer un término específico. En el mismo sentido, el tribunal deberá pronunciarse sin tardanza sobre las objeciones.

En relación con lo anterior, dichos términos son muy cortos dado que la orden preliminar, bajo los lineamientos de la Ley Modelo, expira a los 20 días desde la emisión; mientras que en la Ley 1563 del 2012, esta caduca a los 30 días. Sin embargo, en caso de expirar o caducar la orden preliminar, se podrá otorgar una medida cautelar en búsqueda de ratificar o modificar la orden preliminar, bajo la condición de que se haya notificado a la parte de la orden preliminar.

La Ley Modelo y la Ley 1563 del 2012 suponen un sistema dual, esto quiere decir que la parte debe presentar una doble petición ante el árbitro: por un lado, una solicitud de la orden preliminar y, por otro lado, una solicitud de la medida cautelar. En esta ocasión, quien se vea afectado por la orden preliminar tendrá derecho a defenderse en relación con la petición solicitada. El tribunal arbitral tomará una decisión, ya sea terminando, confirmando o modificando sus términos e incorporando la orden preliminar en la medida cautelar ${ }^{7}$.

La gran distinción entre una orden preliminar y una medida cautelar es que esta última puede ser ejecutable judicialmente; mientras que la orden preliminar no puede llevarse ante una autoridad judicial para su cumplimiento, a pesar de ello, es una orden vinculante para las partes. La medida cautelar se concibe como el medio para garantizar la efectividad del fondo de lo que se discute en el arbitraje; contrario sensu, el fin de la orden preliminar es hacer efectiva la medida cautelar. ${ }^{8}$

Howard M. Holtzmann y Joseph E. Neuhaus. "Uncitral Model Law, Chapter IV.A (Articles 17 - 17J) - as amended [Interim Measures and Preliminary Orders]", en A guide to the 2006 amendments to the Uncitral model law on international commercial arbitration: Legislative history and commentary (Londres: Kluwer Law International, 2015), 172-173.

$7 \quad$ Luis Enrique Graham, "Interim measures: Ongoing regulation and practices (a view from the Uncitral arbitration regime)", en 50 years of the New York Convention: ICCA International Arbitration Conference, ICCA Congress Series, editado por Albert Jan van den Berg (Países Bajos: Kluwer Law International, 2009), 539. 


\begin{tabular}{|c|c|c|}
\hline & Medida cautelar & Orden preliminar \\
\hline $\begin{array}{l}\text { Definición } \\
\text { o propósito }\end{array}$ & $\begin{array}{l}\text { Toda medida temporal, decretada } \\
\text { en forma o no de laudo, en cualquier } \\
\text { momento previo a la emisión } \\
\text { del laudo por el que se dirima } \\
\text { definitivamente la controversia. } \\
\text { Art. } 80 \text {, Ley } 1563 \text { del } 2012 \text {. }\end{array}$ & $\begin{array}{l}\text { El tribunal arbitral podrá emitir } \\
\text { una orden preliminar siempre que } \\
\text { considere que la notificación previa } \\
\text { de la solicitud de una medida cautelar } \\
\text { a la parte contra la cual esa medida } \\
\text { vaya dirigida entrañaría el riesgo de } \\
\text { que se frustre la medida solicitada. } \\
\text { Art. 82, Ley } 1563 \text { del } 2012 \text {. }\end{array}$ \\
\hline $\begin{array}{l}\text { Condiciones } \\
\text { para el } \\
\text { decreto }\end{array}$ & $\begin{array}{l}\text { El solicitante deberá mostrar al tribunal } \\
\text { arbitral la conducencia, pertinencia, } \\
\text { razonabilidad y oportunidad. } \\
\text { Art. 81, Ley } 1563 \text { del } 2012 \text {. }\end{array}$ & $\begin{array}{l}\text { El solicitante deberá mostrar al tribunal } \\
\text { arbitral la conducencia, pertinencia, } \\
\text { razonabilidad y oportunidad. } \\
\text { Art. 81, Ley } 1563 \text { del } 2012 \text {. }\end{array}$ \\
\hline Finalidad & $\begin{array}{l}\text { Mantener o restablecer el statu } \\
\text { quo; impedir algún daño presente } \\
\text { o inminente en el procedimiento } \\
\text { arbitral; preservar bienes; } \\
\text { preservar elementos de prueba. } \\
\text { Art. } 80 \text {, Ley } 1563 \text { del } 2012 \text {. }\end{array}$ & $\begin{array}{l}\text { Busca que una parte no frustre } \\
\text { la finalidad de la medida } \\
\text { cautelar solicitada. } \\
\text { Art. 82, Ley } 1563 \text { del } 2012 .\end{array}$ \\
\hline Caducidad & No tiene caducidad en especial. & $\begin{array}{l}\text { Caducará a los } 30 \text { días contados } \\
\text { a partir de la fecha en que el } \\
\text { tribunal arbitral la haya emitido. } \\
\text { Art. 83, Ley } 1563 \text { del } 2012 \text {. }\end{array}$ \\
\hline Oportunidad & $\begin{array}{l}\text { Se puede decretar antes de la } \\
\text { constitución del tribunal arbitral } \\
\text { o una vez constituido. } \\
\text { Art. } 80 \text {, Ley } 1563 \text { del } 2012 \text {. }\end{array}$ & $\begin{array}{l}\text { Después de haberse pronunciado } \\
\text { sobre la orden preliminar, el tribunal } \\
\text { notificará la medida cautelar. } \\
\text { Art. 83, Ley } 1563 \text { del } 2012 \text {. }\end{array}$ \\
\hline Defensa & $\begin{array}{l}\text { Se puede solicitar que se modifique, } \\
\text { suspenda o revoque la medida cautelar. } \\
\text { Art. 84, Ley } 1563 \text { del } 2012 \text {. }\end{array}$ & $\begin{array}{l}\text { El tribunal arbitral dará la oportunidad } \\
\text { de defenderse y hacer valer sus } \\
\text { derechos en la mayor brevedad posible. } \\
\text { Art. 83, Ley } 1563 \text { del } 2012 \text {. }\end{array}$ \\
\hline Caución & $\begin{array}{l}\text { El tribunal arbitral podrá exigir } \\
\text { del solicitante de una medida } \\
\text { cautelar que preste caución } \\
\text { adecuada respecto de la medida. } \\
\text { Art. 85, Ley } 1563 \text { del } 2012 \text {. }\end{array}$ & $\begin{array}{l}\text { El tribunal arbitral exigirá al peticionario } \\
\text { de una orden preliminar que preste } \\
\text { caución respecto de la orden, salvo que } \\
\text { lo considere inapropiado o innecesario. } \\
\text { Art. } 85 \text {, Ley } 1563 \text { del } 2012 \text {. }\end{array}$ \\
\hline Ejecución & $\begin{array}{l}\text { Admite el reconocimiento y } \\
\text { ejecución de la medida cautelar, } \\
\text { al igual que su denegación. } \\
\text { Art. } 80,88 \text { y } 89 \text {, Ley } 1563 \text { del } 2012 \text {. }\end{array}$ & $\begin{array}{l}\text { No constituye laudo ni es } \\
\text { ejecutable judicialmente. } \\
\text { Art. 83, Ley } 1563 \text { del } 2012 .\end{array}$ \\
\hline $\begin{array}{l}\text { Modificación, } \\
\text { suspensión y } \\
\text { revocación }\end{array}$ & $\begin{array}{l}\text { El tribunal podrá revocar, } \\
\text { suspender o modificar una medida } \\
\text { cautelar decretada, ya sea por } \\
\text { solicitud de las partes o bajo } \\
\text { circunstancias excepcionales, } \\
\text { con notificación a las partes. } \\
\text { Art. 84, Ley } 1563 \text { del } 2012 .\end{array}$ & $\begin{array}{l}\text { El tribunal podrá revocar, } \\
\text { suspender o modificar una orden } \\
\text { preliminar decretada, ya sea por } \\
\text { solicitud de las partes o bajo } \\
\text { circunstancias excepcionales, } \\
\text { con notificación a las partes. } \\
\text { Art. 84, Ley } 1563 \text { del } 2012 \text {. }\end{array}$ \\
\hline
\end{tabular}

Tabla 1. Diferencia entre la medida cautelar y la orden preliminar en la Ley 1563 del 2012 


\section{Tipos de medidas cautelares}

Teniendo en cuenta que las medidas cautelares son una herramienta fundamental para garantizar y asegurar el cumplimiento eventual del laudo, la Ley 1563 del 2012 incluyó diferentes tipos de medidas cautelares.

\section{A) Anticipadas}

En muchos procedimientos arbitrales es necesario tomar medidas cautelares urgentes y anticipadas con el fin de mantener el statu quo o evitar daños irreparables, aun cuando el tribunal arbitral no se ha constituido. Autores como Fouchard, Gaillard y Goldman establecen que las autoridades judiciales son las únicas capaces de tomar medidas urgentes e inmediatamente ejecutables en aquellos casos en los que el tribunal arbitral no se ha constituido. Decretar estas medidas cautelares de carácter urgente no priva al tribunal arbitral de hacer un análisis ni de pronunciarse sobre estas, puesto que el tribunal arbitral no está obligado a seguir el resultado de la autoridad judicial ${ }^{9}$.

En Colombia existe un vacío normativo en lo referente a las medidas cautelares anticipadas, toda vez que la Ley 1563 del 2012 solo presenta el esquema para que se otorguen medidas cautelares una vez el tribunal arbitral ya se ha instalado, pero en caso de que no se haya instalado el tribunal, la ley no indica nada acerca de ello, por ende, se podría acudir a figuras internacionales como el árbitro de emergencia, o a la figura residual de la autoridad judicial.

En relación con lo anterior, por ejemplo, los reglamentos de los Centros de Arbitraje de Bogotá, Medellín y Cali no hacen alusión a quién podrá decretar medidas cautelares de manera anticipada, sin embargo, las partes podrán solicitar medidas cautelares ante una autoridad judicial competente en casos en que el tribunal arbitral no esté todavía integrado.

Recientemente, las cámaras de Comercio de Bogotá, Medellín y Cali aprobaron reformas al Reglamento Interno del Centro de Conciliación, Arbitraje y Amigable Composición, en las cuales se introdujeron distintas disposiciones como el reglamento de arbitraje exprés, siendo este un mecanismo para someter las controversias a arbitraje ante un árbitro único con un procedimiento más expedito.

Philippe Fouchard et al., "Provisional and conservatory measures in the course of the arbitration proceedings", en Goldman on International Commercial Arbitration, Gaillard Fouchard (La Haya, Boston, Londres: Kluwer Law International, 1999), 711. 
No obstante, en estas modificaciones de los reglamentos no se introdujo ni se añadió nada en lo relativo al arbitraje de emergencia ni su posible decreto de manera anticipada por medio de esta figura ${ }^{10}$.

\section{B) Nominadas}

Bajo una figura proteccionista del arbitraje, los tribunales arbitrales pueden emitir medidas cautelares para proteger la propiedad en disputa; los bienes sean embargados y secuestrados en ciertas jurisdicciones; evitar que una parte elimine activos o dinero guardado; la conservación, custodia o venta de bienes o productos; la conservación de bienes en posesión de una parte referidos como secuestro de bienes en otra jurisdicción; la inspección de propiedad; entre otros ${ }^{11}$.

Dentro de las medidas cautelares nominadas están las medidas para facilitar la producción de la prueba ante las autoridades judiciales como en aquella situación en la que una prueba sea relevante para el procedimiento arbitral; medidas para conservar y preservar la prueba, las cuales en muchas circunstancias requieren medidas de carácter urgente; o medidas cautelares para facilitar la ejecución de un laudo arbitral, en las cuales las autoridades judiciales tienen la competencia exclusiva para otorgar este tipo de medidas coercitivas ${ }^{12}$.

Una autoridad judicial o tribunal arbitral podrá solicitar una orden de embargo, el depósito bancario o una garantía para que se cumplan con las obligaciones pecuniarias y se garantice la efectividad futura del laudo arbitral. No obstante, respecto a este punto, la doctrina francesa establece que las órdenes de embargo por parte del tribunal arbitral son parte del proceso de ejecución, las cuales recaen dentro de los poderes de las autoridades judiciales como potestad exclusiva. Hay legislaciones que no establecen taxativamente la potestad del tribunal arbitral de otorgar dichos embargos e ignoran que el tribunal tenga el poder de emitir tales órdenes; no obstante, el simple hecho de que el embargo sea una medida cautelar y esté establecido como una de las facultades del tribunal arbitral para asegurar el statu quo, es razón suficiente para que sea un poder previsto en la ley para los árbitros ${ }^{13}$.

10 Reglamento General del Centro de Conciliación, Arbitraje y Amigable Composición de la Cámara de Comercio de Cali, 27 de agosto del 2020. Reglamento Centro de Arbitraje y Conciliación, Cámara de Comercio de Bogotá, 28 de septiembre del 2019.

11 Howard M. Holtzmann y Joseph E. Neuhaus. "Uncitral model law, chapter IV.A (Articles 17-17J)".

12 Fouchard et al., Goldman on international commercial arbitration (La Haya; Boston; Londres: Kluwer Law International, 1999), 716.

13 Julian David Mathew Lew, Loukas A. Mistelis y Stefan M Kröll, "Interim and conservatory measures", en Comparative international commercial arbitration (La Haya, Países Bajos: Kluwer Law International, 2003), 585-625. 
Conforme se estableció en el caso Cetelem S. A. v. Roust Holdings Limited, las partes tienen derecho a solicitar medidas cautelares para proteger sus derechos, como en aquella situación en la que se vea que existe un riesgo de que desaparezcan pruebas que son importantes en el procedimiento arbitral, entre el inicio y la audiencia. En este caso, para preservar la situación fáctica y legal, salvaguardar los derechos, el Tribunal de Apelaciones de Inglaterra y Gales decretó una medida cautelar en apoyo del arbitraje ante la Cámara de Comercio Internacional - de ahora en adelante $\mathrm{CCl}$ - El Tribunal de Apelaciones ordenó de carácter urgente la medida cautelar para preservar la evidencia o bienes relevantes en el proceso arbitral ${ }^{14}$.

\section{C) Innominadas}

Por otro lado, las medidas cautelares innominadas hacen mención a que el solicitante podrá pedirle al tribunal arbitral cualquier tipo de medida que considere necesaria, sin que esté atada a una medida en particular o expresamente prevista por el legislador. Los distintos instrumentos internacionales otorgan discrecionalidad absoluta a los árbitros para que dicten las medidas cautelares que consideren necesarias para la protección del derecho en el conflicto. En este sentido, las medidas cautelares innominadas otorgan un poder al árbitro para que pueda asegurar la efectividad del resultado procesal de lo que se espera resolver en el arbitraje ${ }^{15}$.

En la Gaceta 321 del 2012 del 6 de junio del Congreso de la República de Colombia como informe de ponencia del segundo debate del proyecto de Ley del Estatuto Arbitral, se estableció que la tendencia actual está encaminada a poder emitir medidas cautelares por medio de medidas innominadas para permitir la tutela anticipada de derechos ${ }^{16}$.

En lo referente a los reglamentos en Colombia, el reglamento de la Cámara de Comercio de Bogotá en el numeral 1 del artículo 3.17 señala que el tribunal arbitral podrá ordenar a cualquiera de las partes la medida cautelar que considere apropiada en el objeto del litigio. En este sentido, este reglamento no nos señala qué tipo de medida cautelar se podrá otorgar, sino que hace mención a

Cetelem S.A. v. Roust Holdings Limited, Civ 618 EWCA (2005).

Cindy Charlotte Reyes-Sinisterra, "Las medidas cautelares anticipatorias e innominadas en el proceso arbitral en Colombia". Revista Vniversitas n. ${ }^{\circ} 132$ (2016): 390-421, https://doi.org/10.11144/ Javeriana.vj132.mcai

Ley 1563 del 2012. Gaceta n. 321 del 2012 del Congreso de la República. Comisión Primera Constitucional, Segundo debate Plenaria. Bogotá, D. C., miércoles, 6 de junio del 2012. 
cualquiera que busque mantener o restablecer el statu quo que se espera dirimir en la controversia.

Para concluir, habiendo explicado y analizado las medidas cautelares innominadas, en el caso Sonera Holding B. V. v. Cukurova Holding A. S., el demandante solicitó una medida cautelar ante la $\mathrm{CCl}$ debido a la urgencia, con el fin de evitar la transferencia de acciones durante el procedimiento arbitral. El tribunal arbitral decretó la medida cautelar ordenando a los demandados no disponer de las acciones sujetas al arbitraje ni tomar otras medidas que pudieran afectar cualquier orden futura relacionada con la transferencia de estas acciones. El tribunal arbitral argumentó que estas medidas cautelares eran procedentes y podían decretarse sin que ello implicara un prejuzgamiento sobre el procedimiento arbitral ${ }^{17}$.

\section{D) Injunction o freezing orders}

La injunction originalmente fue un apremio o una garantía proveniente del derecho inglés de la jurisdicción del equity. El juez al considerar que la parte deudora y dueña de un bien podía ser contumaz en el proceso, le ordenaba el embargo de este bien con el fin de que compareciera al proceso. Esta orden estaba dirigida a la parte contumaz; en sí misma, no tenía que ver con el resultado del proceso ni con la sentencia, sino que era quizás el remedio equitativo más significativo e indispensable para hacer comparecer a la persona al proceso. De esta manera, la orden no la impartía el juez inglés a una autoridad ejecutiva o judicial del exterior, sino a la propia parte.

Con el paso del tiempo, la figura pasó a la jurisdicción del common law, con el famoso caso Mareva Compania Naviera S. A. v. International Bulkcarriers S. A. en el que actuó como magistrado ponente Lord Denning MR. El caso no surgió bajo un arbitraje internacional, originalmente se vio como una ayuda en el litigio del comercio internacional, sin embargo, los tribunales ingleses han sido partidarios de esta orden para ayudar en la ejecución de los laudos derivados de arbitrajes comerciales internacionales ${ }^{18}$.

En el caso Mareva, los demandantes, Compañía Naviera S. A., eran propietarios de un buque el cual se dio mediante un contrato de fletamento a la sociedad International Bulkcarries S. A.; esta última había realizado un subcontrato de

17 Sonera Holding B.V. v. Cukurova Holding A.S., Partial Award. ICC Case No. 13856 (2007).

18 Mareva Compania Naviera SA v. International Bulkcarriers SA', 1 All ER 213 Court of Appeal, Civil Division (1980). 
fletamento con el Gobierno de India. La sociedad pagó las primeras dos cuotas del contrato, sin embargo, incumplió con la tercera, razón por la cual la Compañía Naviera S. A. decidió resolver el contrato. El Gobierno indio había depositado los fletes o cuotas en favor de la demandante, no obstante, la Compañía Naviera S. A. solicitó una injunction para que se prohibiera disponer de estas cuotas o dineros ${ }^{19}$.

Este caso fue importante en el sentido de que el acreedor tiene derecho a que le paguen lo adeudado, bajo la hipótesis de existir un peligro en relación con los activos que vaya a disponer el deudor antes de la sentencia. En la presente situación, los demandados tenían el control sobre una cuenta en el banco de Londres y sobre ella existía un posible riesgo de deshacerse del dinero y sacarlo del país; en caso de que dicha hipótesis sucediera, los demandantes nunca tendrían su buque de vuelta, al igual que su dinero. Ante este riesgo, el tribunal debía otorgar una orden judicial para evitar que los demandados dispusieran de este dinero. Al final, los tres jueces estuvieron de acuerdo con la orden propuesta por Lord Denning MR, la cual buscaba que el acusado en el extranjero no retirara sus activos de la jurisdicción del tribunal inglés ${ }^{20}$. En síntesis, la injunction fue dirigida a la parte demandada, so pena de multa, y no al banco o una autoridad judicial.

\section{E) Anti suit injunction}

Este proceso de la anti-suit injunctions - de ahora en adelante ASI- es muy similar al explicado con las injunctions, pues la parte puede solicitar ante un tribunal arbitral o una autoridad judicial que la contraparte se abstenga de iniciar o continuar un proceso ante otra jurisdicción con el fin de que el trámite arbitral que se está desarrollando no sea burlado ni irrisorio y que con ello la sentencia o el laudo se pueda cumplir.

A pesar de que, en el origen de las ASI, conforme al sistema del common law, se dirigía contra una parte y no contra una autoridad judicial para que se abstuviera de iniciar un proceso ante otra jurisdicción, en diversos casos (los cuales se analizarán a continuación) se ha reflejado que las ASI pueden estar dirigidas contra los tribunales arbitrales o autoridades judiciales. Si una parte ha presentado una demanda ante la autoridad judicial, en la cual existe una cláusula arbitral, se ordenará Justice” (España: La Ley 2010, 2010).

20 Lawrence F. Ebb, "Flight of assets from the jurisdiction 'in the twinkling of a telex': Pre-and post-award conservatory relief in international commercial arbitrations". Journal of International Arbitration n. 7 (1): (1990) 9-36. 
que se retire o suspenda el proceso, ya que busca evitar litigios ventajosos u opresivos en el extranjero ${ }^{21}$.

En caso que un tribunal arbitral con sede en Colombia reciba una ASI por parte de una autoridad judicial de otro Estado, en la que se le solicite abstenerse de iniciar o continuar un proceso arbitral, ¿esta orden puede ser considerada una medida cautelar? La definición de una ASI no cabría dentro de la definición que nos da la Ley 1563 del 2012 acerca de medidas cautelares, toda vez que las medidas cautelares buscan garantizar aquello que se espera del proceso arbitral; mientras que las ASI esperan preservar el mecanismo que las partes han acordado para la solución de las controversias, es decir, defender el mecanismo al restringir a una parte de intentar eludir su obligación de ir a arbitraje.

La Ley Modelo no hace alusión a las ASI, sin embargo, el artículo 5 establece que en los asuntos de arbitraje no deberá intervenir ninguna autoridad judicial, salvo en los casos que expresamente así lo disponga, casos en los cuales las autoridades judiciales intervendrán en asistencia del proceso arbitral o del control de legalidad.

Para comenzar, en el caso Allianz SpA and Generali Assicurazioni Generali SpA v. West Tankers Inc. se tenía un buque de propiedad de West Tankers y Erg Petroli SpA el cual provocó daños contra un embarcadero; este contrato tenía cláusula arbitral con sede en Londres, Erg Petroli SpA acudió a sus aseguradoras Allianz y Generali e inició un procedimiento arbitral en contra de West Tankers. Más adelante, Allianz y Generali interpusieron una demanda contra West Tankers ante el Tribunal de Siracusa en Italia para reclamar los daños causados. Paralelamente, West Tankers inició un procedimiento ante la Corte Suprema de Justicia en Inglaterra y Gales y ante el Queen's Bench Division con el fin de suspender el litigio desarrollado en Italia y cumplir con el acuerdo de arbitraje. West Tankers solicitó una ASI ante la Corte Suprema de Justicia de Inglaterra y de Gales para que se prohibiera que Allianz y Generali instauraran un procedimiento que no fuera el de arbitraje 22 .

Sin embargo, Allianz y Generali apelaron la ASI ante la Cámara de los Lores, en la cual se determinó que la ASI privaba a los tribunales de Italia a decidir acerca de su propia jurisdicción, según lo que establece el Reglamento del Convenio de

21 Julián David Matthew Lew, "Control jurisdiction by injunctions issued by National Courts", en International arbitration 2006: Back to basics, editado por Albert Jan van den Berg (Montreal: Kluwer Law International, 2007), 185-220. 
Bruselas I relativo a la competencia judicial, el reconocimiento y la ejecución de resoluciones judiciales. Esta Cámara determinó que las ASI emitidas por los dos tribunales de la Unión Europea eran incompatibles con el reglamento, dado que bajo ninguna circunstancia un tribunal de la Unión Europea estaba en mejores circunstancias que la otra corte o tribunal. Por ende, los tribunales de la Unión Europea, concretamente el de Inglaterra e Italia, no tenían derecho a hacer cumplir los acuerdos de arbitraje a través de las ASI, las cuales buscaban evitar que una parte iniciara o continuara con los procedimientos ante otra autoridad judicial.

En síntesis, la jurisprudencia de los tribunales de la Unión Europea y los Reglamentos del Convenio de Bruselas, establecen que los tribunales de los Estados miembros no tendrán que ejecutar y adoptar las ASI que han sido dictadas por tribunales de otro Estado miembro de la Unión Europea, dado que el Reglamento del Convenio de Bruselas I no autoriza la competencia mutua de un tribunal de un Estado miembro con el tribunal de otro Estado; al igual, iría en contra del principio de confianza mutua ${ }^{23}$.

El segundo caso relevante hace alusión a las anti ASI (o anti anti-suit injunction), la cual es una orden contra una ASI otorgada por un tribunal o autoridad judicial para detener a una medida cautelar que está solicitando una parte en otro tribunal o autoridad judicial. En el caso KBC v. Pertamina los tribunales de Indonesia y Estados Unidos ordenaron respectivamente una ASI y una anti ASI24.

El conflicto surgió entre la empresa de Indonesia, llamada Pertamina, y KBC, contratista de una planta geotérmica en Indonesia. Para comenzar, la empresa KBC inició un procedimiento arbitral en Suiza de conformidad con la cláusula arbitral, el tribunal arbitral ordenó a Pertamina a pagar daños y perjuicios a KBC. Después, en el 2001, Pertamina presentó dos solicitudes: la primera referente a la anulación del laudo conforme a la Convención de Nueva York — de ahora en adelante CNY— ante el Tribunal del Distrito Central de Yakarta en Indonesia; la segunda, una orden judicial que prohibía a KBC hacer cumplir el laudo en el extranjero. A su vez, KBC estaba solicitando el reconocimiento del laudo ante el Tribunal de Distrito de los Estados Unidos para el Distrito Sur de Texas.

March Rich, "El arbitraje y el Reglamento de Bruselas I Refundido, las anti-suit injunction, y ahora el Brexit". Osborne Clarke LLP (blog), acceso 5 de diciembre del 2010, https://www.osborneclarke. com/wp-content/uploads/2016/11/El-Arbitraje-y-el-Reglamente-Bruselas-I-Refundido-las-AntiSuit-Injunction-y-ahora...-el-Brexit.pdf

Emmanuel Gaillard, "Reflections on the use of anti-suit injunctions in international arbitration," en Pervasive problems in international arbitration, editores Loukas A. Mistelis y Julian David Matthew Lew (Países Bajos: Kluwer Law International, 2006), 201-213. 
Finalmente, el Tribunal de Yakarta anuló el laudo al considerar que era contrario a la CNY y a la ley de arbitraje de Indonesia y emitió una ASI en donde prohibía a KBC hacer cumplir el laudo en el extranjero. Ante esta situación, KBC solicitó una anti ASI ante los Tribunales de Estados Unidos para que Pertamina suspendiera y retirara la orden judicial solicitada ante los Tribunales de Indonesia.

Este caso fue de gran importancia toda vez que cada parte se enfrentó a una orden judicial en contra del laudo arbitral en distintas jurisdicciones como en Estados Unidos para Pertamina y en Indonesia para KBC, al igual que se impusieron sanciones pecuniarias como medida de desacato por parte del Tribunal de Distrito de Texas para Pertamina y del Tribunal de Indonesia para KBC, al no haber ejecutado la orden judicial correspondiente. En esta ocasión, las ASI y anti ASI no fueron claras, como no se cumplieron dichas ordenes en contra de las demandas instauradas, los tribunales emitieron un desacato para cada una de las partes, toda vez que las solicitudes ante los tribunales de Indonesia y Estados Unidos no tuvieron mucho efecto. A pesar de que el Tribunal de Indonesia actuó incorrectamente en su decisión de anular el laudo, el Tribunal de Estados Unidos determinó que igual se puede ejecutar el laudo en el extranjero, razón por la cual el tribunal estableció que la ASI era ilegítima.

En suma, la injunction empezó como un remedio de equity para obligar a un demandado a comparecer, al ser una medida del common law en la que el juez ordena a una parte a abstenerse de ejecutar un hecho, generalmente no disponer de sus bienes para que la sentencia pueda ser cumplida. Hoy en día, los jueces también utilizan las injunctions para ordenar a otro juez o árbitro que se abstengan de iniciar o continuar un proceso igual entre las mismas partes. Las ASI, por su parte, son órdenes judiciales o arbitrales orientadas a controlar las injuntions.

En un mundo en que no hay jerarquía entre los jueces de los diversos Estados, el principio fundamental para resolver el problema de las injuntions y las ASI es el denominado Kompetenz-Kompetenz que establece que el árbitro es juez de su propia competencia.

\section{Decreto y práctica}

La facultad que tiene una autoridad judicial para ordenar medidas cautelares es una cuestión que depende de la lex arbitri y del reglamento de arbitraje. En general, el tribunal arbitral es el competente para decretar las medidas cautelares solicitadas 
por las partes, teniendo en cuenta que está en mejor posición. Sin embargo, no todos los tribunales están facultados para ordenar medidas cautelares conforme a la legislación nacional o a lo acordado por las partes, razón por la cual se justifica que sea la autoridad judicial que decrete y ejecute las medidas cautelares ${ }^{25}$.

En algunas circunstancias el tribunal arbitral carece de poder coercitivo, por lo que el tribunal arbitral deberá recurrir a la autoridad judicial para que reconozca y aplique la medida. Esto se ve reflejado cuando se solicita una medida cautelar antes de que se constituya el tribunal arbitral a través de una autoridad judicial, o incluso en determinadas circunstancias después de la constitución del tribunal ${ }^{26}$.

\section{A) Jurisdicción concurrente}

El propósito del artículo 17J de la Ley Modelo, al igual que el artículo 90 de la Ley 1563 del 2012, es señalar que la autoridad judicial tiene la facultad para emitir medidas cautelares en los procedimientos arbitrales pendientes, sin importar si el procedimiento se lleva a cabo en la sede del arbitraje o se está llevando en otra jurisdicción. El Grupo de Trabajo en la realización de las enmiendas de la Ley Modelo en el 2006 señaló que había incertidumbre en muchas jurisdicciones acerca del cuestionamiento si las autoridades judiciales estaban o no autorizadas para emitir medidas cautelares en apoyo del arbitraje cuando había un acuerdo de arbitraje que era válido ${ }^{27}$.

Solicitar una medida cautelar ante una autoridad judicial no implica que las partes renuncien a la cláusula de arbitraje, dado que el decreto y la práctica de las medidas cautelares no es un ejercicio exclusivo de un tribunal arbitral ni supone una negación al pacto arbitral28, así lo establece el artículo 9 de la Ley Modelo. En este mismo sentido, en muchos casos el acuerdo de arbitraje deja claro que la intervención por parte de la autoridad judicial no significa que se busque evitar el desarrollo del arbitraje. La Ley Modelo por medio del artículo 17 buscó señalar que las órdenes emitidas por parte de los tribunales arbitrales se reconozcan como 2006), 155-183. as Amended. Interim Measures and Preliminary Orders". 
vinculantes ante una autoridad competente, independientemente del país en el que se emitió ${ }^{29}$.

No obstante, en el acuerdo de arbitraje las partes pueden acordar la exclusión de la facultad dirigida al tribunal arbitral de decretar y practicar las medidas cautelares, y, por el contrario, entender que el poder de decretar las medidas cautelares sea exclusivamente de un foro o de la autoridad judicial. Pese a esta estipulación, es inusual que en la práctica las partes excluyan al tribunal arbitral de la facultad de otorgar medidas cautelares. Lo que se podría discutir es que exista una jurisdicción concurrente para ordenar medidas cautelares entre la autoridad judicial y los tribunales arbitrales, sin considerar una exclusión del poder del tribunal arbitral, a pesar de que se les dé la posibilidad a las partes de pactar libremente lo que ellos consideren necesario para el proceso arbitral ${ }^{30}$.

Por medio de la decisión del caso Blumenthal v. Merrill Lynch, el Segundo Circuito de la Corte de Apelaciones de los Estados Unidos decidió que la autoridad judicial puede decretar medidas cautelares en ayuda del arbitraje con el fin de preservar la importancia del arbitraje y no obstruir su ejecución. La ayuda de una autoridad judicial respecto de las medidas cautelares no afectará el acuerdo de arbitraje, puesto que el acuerdo de las partes no aborda expresamente la disponibilidad de las medidas cautelares ordenadas por la autoridad judicial en ayuda del arbitraje. En este sentido, se rechazó el argumento de que una autoridad judicial solo pueda actuar en el arbitraje respecto al decreto de las medidas cautelares cuando el contrato así lo estipule expresamente ${ }^{31}$.

Por otro lado, en el caso Ku-Ring-Gai Council v. Ichor Constructions Pty Ltd. la Corte de Apelaciones de Nueva Gales del Sur en Australia señaló que la autoridad judicial, conforme a los lineamientos de la lex arbitri, tiene poderes para decretar medidas cautelares en el arbitraje, ya que goza de las mismas competencias que el tribunal arbitral. También, la facultad que tiene la autoridad judicial para decretar medidas cautelares busca prevenir daños y perjuicios actuales o inminentes en el proceso arbitral. La decisión realizada por la autoridad judicial se hizo "en ayuda del proceso arbitral porque se relacionaba la facultad del árbitro". La Corte de Apelaciones concluyó que los trabajos preparatorios del Grupo de Trabajo de la Ley Modelo, tenían la intención de declarar la compatibilidad entre resolver una disputa arbitral (Bogotá: Universidad Externado de Colombia, 2013), 345-433.

30 Gary B. Born, "Provisional relief in international arbitration", en International commercial arbitration (Londres: Kluwer Law International, 2014), 2424-2563. 
a través de arbitraje y al mismo tiempo ayudar al tribunal para la protección del proceso por medio de medidas cautelares ${ }^{32}$.

\section{B) La intervención del juez es residual}

La intervención del juez es residual y deberá decretar o ejecutar la medida cautelar basada en el acuerdo de arbitraje que se tiene y en lo establecido en la ley. La autoridad judicial tiene injerencia en el proceso arbitral internacional en lo referente a las medidas cautelares, dado que en ciertos casos el decreto y la ejecución depende de la correspondiente autoridad judicial. No obstante, su intervención debe ser residual y se le debe dar la facultad al árbitro de resolver su competencia y sus facultades; la autoridad judicial debe apoyar el arbitraje teniendo en cuenta la normativa internacional, sin necesidad de acudir a fuentes locales que no vienen a colación.

El artículo 68 de la Ley 1563 del 2012 faculta a los jueces de la jurisdicción ordinaria y de lo contencioso administrativo a participar dentro del proceso arbitral internacional, el juez civil del circuito será el competente para conocer y participar en procesos arbitrales en los que se traten temas referentes a personas naturales o jurídicas siempre y cuando estas sean privadas; mientras que cuando se trate de arbitrajes referentes a controversias derivadas de contratos estatales será la jurisdicción de lo contencioso administrativo.

El Tribunal Supremo de Singapur en apelación en el caso NCC International $A B$ v. Alliance Concrete Singapore Pte Ltd. estableció que tiene jurisdicción concurrente con el tribunal arbitral para ordenar medidas cautelares en los arbitrajes internacionales; el Tribunal Supremo, en caso de decretar una medida cautelar, evitará usurpar las funciones del tribunal arbitral y solo ordenará las medidas con el fin de ayudar, promover y apoyar el procedimiento arbitral. Sin importar cuál es el reglamento aplicado, la autoridad judicial intervendrá solo con moderación y en circunstancias muy limitadas como en aquellos casos en que el tribunal arbitral no pueda constituirse lo suficientemente rápido, razón por la cual se requieren poderes de la autoridad judicial. En este sentido, el Tribunal Supremo anotó que su intervención sería limitada por dos razones: primero, se da prioridad al tribunal arbitral para decretar medidas cautelares teniendo en cuenta que el poder de la autoridad judicial es incidental al del tribunal, e intervendrá solo con moderación 
y en circunstancias limitadas; segundo, las funciones asignadas a la autoridad son meramente de apoyo ${ }^{33}$.

\section{Intervención del árbitro de emergencia}

El árbitro de emergencia es una figura que se utiliza en casos de urgencia específicamente para decretar medidas cautelares en aquellas circunstancias en las que las partes no pueden esperar a la constitución del tribunal arbitral, razón por la cual acuden a un árbitro de emergencia para que, por medio de una orden rápida y expedita, decida sobre la medida cautelar. Diversas instituciones como que la $\mathrm{CCl}$, American Arbitration Association (AAA), Hong Kong International Arbitration Centre (HKIAC), Singapore International Arbitration Centre (SIAC) y Uncitral prevén la figura del árbitro de emergencia dentro de sus reglamentos.

La aplicación de las medidas cautelares ordenadas por un árbitro de emergencia tiene plena eficacia puesto que es un árbitro con poderes temporales que solo actúa en caso de urgencia. La decisión de un árbitro sobre las medidas cautelares puede estar reflejada en un laudo o no, por ende, las medidas cautelares emitidas por un árbitro de emergencia deben estar sujetas al reconocimiento y ejecución de la misma manera que las decisiones de un tribunal arbitral ${ }^{34}$.

No todas las autoridades judiciales están integradas con jueces especializados para que conozcan del tema; por ende, presentar una solicitud de una medida cautelar ante un juez que no es consciente de la importancia de cierta medida puede generar problemas, por esta razón es que las instituciones arbitrales han dado la posibilidad de que un árbitro de emergencia especializado en el área de la disputa decrete la medida cautelar. Autores como Ali Yeşilirmak señalan que solicitar la medida cautelar a una autoridad judicial es pedirle a una parte hacer algo que no quiere, toda vez que estas han decidido someter su controversia a arbitraje por múltiples razones ${ }^{35}$.

\footnotetext{
33 NCC International AB v. Alliance Concrete Singapore Pte Ltd, 2 SLR(R) 565 (2008).

34 Gary B. Born. 2014. "Provisional relief in international arbitration", en International commercial arbitration (Londres: Kluwer Law International, 2014), 2424-2563.

35 Ali Yesilirmak, Provisional measures in international commercial arbitration (Kluwer Law International, 2005) en Rania Alnaber, "Emergency arbitration: Mere innovation or vast improvement". Oxford University Press, volumen 35, issue 4, (2019): 441-472.
} 
Según Rania Alnaber, ver al árbitro de emergencia y a la autoridad judicial como autoridades idénticas es difícil, puesto que las facultades y funciones del árbitro de emergencia son similares a las que tiene un tribunal arbitral en relación con el decreto de las medidas cautelar, sin embargo, la función del árbitro de emergencia es apoyar de manera transitoria la emisión de las medidas para lograr la efectividad del laudo final ${ }^{36}$.

\section{A) Ejecución de la decisión del árbitro de emergencia}

La exigibilidad de la decisión acerca de las medidas cautelares por parte de los árbitros de emergencia no está en duda, las medidas cautelares se pueden cumplir conforme a lo establecido en la Ley 1563 del 2012 y Ley Modelo para el reconocimiento y la ejecución de medidas cautelares. La decisión del árbitro de emergencia no es final, sino provisional, dado que será analizada por parte del tribunal arbitral después.

La mayoría de las legislaciones no reconocen explícitamente la figura del árbitro de emergencia, ya que son los reglamentos de las distintas instituciones los que exploran este tipo de opción. A pesar de esto, esta figura del árbitro de emergencia puede aplicarse bajo el análisis de que las medidas cautelares dictadas por ellos tienen el mismo propósito que las dictadas por el tribunal arbitral.

En el caso Chinmax Medical Systems Inc v. Alere San Diego, Chinmax era distribuidor de dispositivos médicos fabricados por Alere San Diego. Alere San Diego afirmó que Chinmax había incumplido el acuerdo de distribución. Alere San Diego presentó ante un árbitro de emergencia una solicitud de medida cautelar de conformidad al Reglamento del International Center for Dispute Resolution (ICDR). Dicha medida cautelar buscaba garantizar que Chinmax renovara de manera oportuna el registro del producto, entregara un depósito de garantía y transmitiera copias de las solicitudes del registro de los productos o la renovación de los mismos. En esta ocasión, Chinmax se opuso a la petición alegando que el árbitro de emergencia no tenía la jurisdicción para emitir una medida cautelar teniendo en cuenta que el acuerdo arbitral solo facultaba al tribunal arbitral. El Tribunal del Distrito de California negó la solicitud de Chinmax y aceptó la medida cautelar decretada por el árbitro de emergencia ${ }^{37}$.

Rania Alnaber, "Emergency arbitration: Mere innovation or vast improvement". Oxford University Press, volumen 35, issue 4, (2019): 441-472. 
El último caso relevante es el caso Yahoo! Inc. v. Microsoft Corporation ${ }^{38}$. En el 2009 Microsoft y Yahoo! realizaron un acuerdo para juntar su capacidad de búsqueda internacional a través de internet con el fin de competir con Google. Las partes originalmente acordaron que en el 2011 comenzaría la implementación del acuerdo en Taiwán y Hong Kong, sin embargo, por problemas técnicos se produjeron múltiples retrasos. En el 2013 la transacción estaba lista para comenzar, no obstante, en septiembre de dicho año Yahoo! informó a Microsoft que la transacción no estaba siendo realizada puesto que había que esperar a la implementación en Taiwán y Hong Kong, la cual se realizaría a principios del 2014. Microsoft consideró que la actuación de Yahoo! con el programa de búsqueda era una violación al acuerdo entre las partes. Microsoft solicitó ante un árbitro de emergencia de la AAA una medida cautelar en la que se le ordenaba a Yahoo! que hiciera todo lo posible para completar la transacción de Taiwán y Hong Kong. En esta ocasión, el árbitro de emergencia decretó y concedió la solicitud de Microsoft de medidas cautelares, toda vez que Yahoo! había violado el acuerdo entre las partes.

\section{B) Árbitro de emergencia y la jurisdicción concurrente}

Las medidas cautelares que decretan los árbitros de emergencia buscan ser de carácter urgente, sin que delibere sobre los méritos de la disputa. En este caso, el árbitro será responsable de cualquier pérdida o daño causado tras la emisión de la medida cautelar. Según Fouchard, Gaillard y Goldman cuando se establece una cláusula de arbitraje con un árbitro de emergencia, las partes renuncian a los derechos de solicitar medidas cautelares ante las autoridades judiciales en la jurisdicción que se encuentre el arbitraje o el árbitro de emergencia. Esta estipulación es legítima y puede ser entendida como la intención de las partes de acudir a un árbitro para decretar las medidas cautelares, toda vez que las partes han optado por acudir a procedimientos acelerados ${ }^{39}$.

\section{C) Condiciones para la aplicación de medidas cautelares con árbitros de emergencia}

El primer criterio para que el árbitro de emergencia pueda otorgar una medida cautelar de carácter urgente es que el tribunal arbitral no se haya constituido. Sin 
embargo, la decisión sobre esta medida será restrictiva y no podría interpretarse como un permiso sobre todo el arbitraje. La condición de que el tribunal arbitral no se haya constituido es razón suficiente para justificar que sea el árbitro de emergencia quien bajo una decisión rápida expida la medida cautelar ${ }^{40}$.

El segundo criterio importante para que se pueda ordenar esta medida cautelar es que sea urgente su decreto, razón por la cual no se pueda esperar a la constitución del tribunal arbitral, sin que implique que por la decisión sobre la urgencia el árbitro de emergencia tenga competencia para conocer sobre los méritos de la controversia ${ }^{41}$.

La mayoría de los árbitros de emergencia, al analizar la urgencia de la medida cautelar, exigen que la parte solicitante demuestre los siguientes requisitos: un riesgo de un daño grave o irreparable; una urgencia, es decir que la parte no podrá esperar a la constitución del tribunal arbitral para su decreto; y que esta no prejuzgue los méritos de lo que se espera resolver en la disputa arbitral ${ }^{42}$. En este sentido, para que se otorguen medidas cautelares por parte de un árbitro de emergencia, las partes que solicitan la medida cautelar deberán demostrar que existe una urgencia que no puede esperar hasta la constitución del tribunal arbitral por los riesgos de daños irreparables o graves ${ }^{43}$.

Los distintos reglamentos de los centros arbitrales como la CCI, SCAI, SCC, AAA, HKIAC, SIAC, Uncitral, entre otros, establecen la figura del árbitro de emergencia bajo la circunstancia en la cual las partes no pueden esperar a la constitución de un tribunal arbitral para el decreto de la medida cautelar de carácter urgente, razón por la cual acuden a las distintas instituciones que van a regir el arbitraje que ha sido pactado por las partes, para que se nombre a un árbitro de emergencia que tenga la potestad de ordenar una medida cautelar mientras se constituye del tribunal arbitral. Sin embargo, la orden emitida por el árbitro de emergencia no limita la competencia del tribunal arbitral, ya que una vez el tribunal esté constituido tendrá la competencia para analizar si confirma, modifica o deniega la medida cautelar otorgada en aquel momento.

Haciendo una lectura de los distintos reglamentos de arbitraje comercial internacional se ve que Colombia tiene un déficit en la figura del árbitro de emergencia

$40 \quad$ Fouchard et al., 1999.

41 Ibidem.

42 Gary B. Born, "Provisional relief in international arbitration", en International commercial arbitration (Países Bajos: Kluwer Law International, 2014), 2424-2563.

43 Philippe Cavalieros y Janet Kim, “Emergency arbitrators versus the Courts: From concurrent jurisdiction to practical considerations", Journal of International Arbitration 35 (3): (2018) 275-306. 
para situaciones como la medida cautelar. Los reglamentos del país no estipulan la figura de árbitro de emergencia, en lo que se refleja que es una ventaja importante en los reglamentos internacionales. En este sentido, es importante que en la normativa colombiana se reglamenten preceptos concernientes al árbitro de emergencia. Así, establecer este parámetro en los reglamentos de arbitraje en Colombia, ayudaría a que se acuda a la figura del árbitro de emergencia como primera medida, y de manera residual ante la autoridad judicial.

\section{Reconocimiento o ejecución de las medidas cautelares}

La Ley Modelo y la Ley 1563 del 2012 prevén la posibilidad de que las partes que busquen el reconocimiento y la ejecución en otro país de las medidas cautelares que han sido decretadas por el tribunal arbitral en la sede.

Para comenzar, vale la pena establecer la diferencia entre reconocimiento y ejecución de la medida cautelar. En la ley colombiana, antes con el Código de Procedimiento Civil, se hablaba de exequátur, el cual comprendía el reconocimiento y la ejecución; sin embargo, con el Código General del Proceso y la Ley 1563 del 2012 se habla de reconocimiento y ejecución. El reconocimiento de la medida cautelar puede surtir efectos en Colombia sin necesidad de acudir al aparato judicial colombiano, en este sentido, la Ley 1563 del 2012 dice que toda medida cautelar decretada por un tribunal arbitral será reconocida sin necesidad de un procedimiento alguno; mientras que, en la ejecución, la misma ley establece que se requiere el uso del aparato judicial colombiano, por ende, se solicita la ejecución ante la autoridad judicial.

Por lo tanto, una medida cautelar ejecutada en Colombia necesariamente e implícitamente está reconocida con anterioridad, sin embargo, una medida puede estar reconocida pero no estar ejecutada dado que no se acudió al aparato judicial para ello. En este sentido, toda medida cautelar ejecutada está reconocida, no obstante, puede haber reconocimiento sin ejecución.

Ahora bien, el artículo 88 de la Ley 1563 del 2012 establece que toda medida cautelar decretada por un tribunal arbitral se reconocerá como vinculante sin necesidad de un procedimiento para su reconocimiento, salvo que se requiera la ejecución ante la autoridad judicial, en la que se procederá a realizar la ejecución de la medida cautelar decretada pero no deberá ir en contra de las causales de denegación de las medidas cautelares. La parte que solicita la ejecución ante la 
autoridad judicial, deberá informar cualquier revocación, suspensión o modificación de la medida cautelar que disponga el tribunal arbitral, so pena de rechazo.

Una gran diferencia entre la orden preliminar y la medida cautelar es que solo la segunda es sujeta de reconocimiento y ejecución por parte de una autoridad judicial, aun así, las ordenes preliminares son obligatorias y vinculantes para las partes, pero no pueden llevarse ante una autoridad judicial para su cumplimiento ${ }^{44}$.

La autoridad judicial en la que se esté solicitando el reconocimiento y la ejecución de la medida cautelar, al tomar una consideración, no deberá realizar una revisión sustancial de la medida cautelar ni mucho menos analizar el fondo de la controversia. Con ello se busca que en la etapa de ejecución de la medida cautelar, la competencia del tribunal o autoridad judicial que analiza esta medida cautelar no se extienda al fondo del asunto, ya que esto está dentro de la competencia del tribunal arbitral ${ }^{45}$.

En el mismo sentido, en el caso Coal India Limited v. Canadian Commercial Corporation, se analizó que hay operaciones extraterritoriales en donde se necesita una cooperación de otras jurisdicciones para el reconocimiento y ejecución de las medidas cautelares. Así pues, "para que una orden sea efectiva, la parte que busca la ejecución de esta medida cautelar debe acercarse a la autoridad competente de un país que podría hacer que la medida cautelar sea real", por ende, la autoridad judicial competente a la que se debe recurrir para el reconocimiento y ejecución, por lo general es la del país en donde la otra parte tiene sus activos ${ }^{46}$.

\section{Causales de no ejecución de las medidas cautelares}

El artículo 89 de la Ley 1563 del 2012 indica los motivos para denegar la ejecución de las medidas cautelares que hayan sido decretadas por el tribunal arbitral. La autoridad judicial solo podrá denegar la ejecución de una medida cautelar en casos específicos estipulados taxativamente en el artículo mencionado. El objetivo de

$44 \quad H o w a r d$ M. Holtzmann y Joseph E. Neuhaus. "Uncitral Model Law, Chapter IV.A (Articles 17 - 17J) - as amended [Interim Measures and Preliminary Orders]", en A guide to the 2006 amendments to the Uncitral model law on international commercial arbitration: Legislative history and commentary (Londres: Kluwer Law International, 2015) 210.

45 Luis Enrique Graham, "Interim measures: Ongoing regulation and practices (a view from the Uncitral arbitration regime)", en 50 Years of the New York Convention: ICCA International Arbitration Conference, ICCA Congress Series, editado por Albert Jan van den Berg (Londres: Kluwer Law International, 2009), 539-569.

46 Coal India Limited v. Canadian Commercial Corporation, 172 High Court of Judicature at Calcutta (2002). 
establecer taxativamente las causales de denegación de las medidas cautelar tiene como objeto limitar el número de circunstancias en las que la autoridad judicial podrá denegar la ejecución de la medida cautelar. Por ende, no se menoscabarían los derechos si cada Estado, en su legislación, prevé supuestos menos estrictos que los de la Ley Modelo para denegar la medida cautelar.

Dichas causales para denegar la medida cautelar, mutatis mutandis, son las mismas que las causales que establece la ley para la denegación del reconocimiento y ejecución de laudos arbitrales. En este caso, la autoridad judicial solo podrá pronunciarse respecto de los motivos enunciados en el artículo mencionado, es decir, solo se pronunciará sobre la existencia de las causales y no sobre el contenido de la medida cautelar.

Las causales de denegación de las medidas cautelares están previstas en el artículo 89 de la Ley 1563 del 2012 y en el artículo 17I de la Ley Modelo en la que traen una enumeración de los motivos por los cuales una autoridad judicial solo puede denegar una medida cautelar conforme a las causales ahí expuestas. Los motivos de denegación de las medidas cautelares están divididas en dos categorías: la primera, los motivos que deben ser alegados y probados por la parte; y la segunda, los motivos que puede conocer la autoridad judicial de oficio. Conforme al Grupo de Trabajo, las causales de denegación de medidas cautelares son las que se establecen en la Ley con el objetivo de "limitar el número de circunstancias en las que el tribunal puede negarse a aplicar una medida cautelar". ${ }^{47}$

El Grupo de Trabajo, al realizar las enmiendas de la Ley Modelo en el 2006 y analizar los motivos para denegar la ejecución de la medida cautelar, estableció que, en vez de realizar una redacción de los artículos de denegación de las medidas cautelares, era mejor dirigirse y aplicar los artículos de reconocimiento, ejecución y denegación de laudo arbitral para las medidas cautelares, toda vez que ofrecía una redacción más concisa, al igual que limitaba el riesgo ${ }^{48}$.

De hecho, Uncitral, para lograr una uniformidad, ha proyectado una identidad, mutatis mutandis, entre las causales para denegar el exequátur de laudos arbitrales en la CNY, las causales para anular un laudo arbitral y las causales para denegar la ejecución de medidas cautelares en la Ley Modelo.

Como se estableció previamente, las causales para denegar el reconocimiento o la ejecución de las medidas cautelares se dividen en dos categorías: en del law on international commercial arbitration: Legislative history and commentary (Kluwer Law International, 2015). 
primer lugar, los motivos a solicitud de parte en donde la misma debe alegarlos y probarlos, los cuales hacen referencia a que el acuerdo de arbitraje no existe o no es válido; la falta de notificación; la decisión no está prevista en el acuerdo arbitral; la composición del tribunal arbitral o el procedimiento no se ajustó al acuerdo; no se ha cumplido con la caución de la medida cautelar decretada; o la medida haya sido revocada o suspendida. En segundo lugar, están los motivos en que la autoridad judicial puede conocer de oficio, cuando el objeto o materia del proceso no es susceptible de arbitraje; o hay una violación al orden público internacional.

\section{A) El acuerdo de arbitraje no existe o no es válido}

La mayoría de los estatutos de arbitraje permiten que se deniegue el reconocimiento de medidas cautelares cuando no haya un acuerdo de arbitraje válido entre las partes en el arbitraje. Es elemental que en el arbitraje la cláusula arbitral conste por escrito; no habrá tribunal arbitral, a menos que las partes hayan acordado válidamente arbitrar una disputa ${ }^{49}$.

Los árbitros no pueden decretar medidas cautelares cuando no exista un acuerdo arbitral entre las partes puesto que no tendrían la facultad de actuar en un proceso arbitral y, por ende, de decretar medidas cautelares. En este sentido, cuando no exista o no sea válido el acuerdo de arbitraje, el afectado con la medida cautelar podrá solicitar ante la autoridad judicial que se deniegue, y, por ende, que no se reconozca ni se ejecute. Un supuesto que podría darse es que exista, pero no sea válido el pacto arbitral por la falta de capacidad de las partes, causa u objeto ilícito, o falta de consentimiento; por lo tanto, si no hay validez del acuerdo de arbitraje, se podría solicitar la denegación de la medida cautelar. Sobre este particular, el literal a. del artículo V de la CNY de 1958 defiere lo relativo a la capacidad para la celebración del pacto arbitral a la ley aplicable a dicho pacto ${ }^{50}$.

\section{B) Falta de notificación}

La segunda causal de denegación de la medida cautelar hace referencia a la indebida notificación de la iniciación de la actuación arbitral. La parte que no fue notificada debidamente acerca del nombramiento del árbitro o de los procedimientos

Gary B. Born, "Recognition and enforcement of international arbitral awards", en International commercial arbitration (Londres: Kluwer Law International, 2014).

50 Convención sobre el reconocimiento y la ejecución de las sentencias arbitrales extranjeras, 1958, Nueva York. Literal a., artículo V. 
arbitrales o no pudo presentar su caso, podrá solicitar la denegación de la medida cautelar. Por ende, se justifica la denegación de la medida cautelar por una violación del debido proceso ${ }^{51 .}$

Esta causal hace referencia al derecho que tiene la parte de solicitar la denegación de la medida cautelar cuando no haya podido hacer valer sus derechos y defenderse en el proceso arbitral, recoge también una indebida notificación en la designación de los árbitros o cualquier indebida notificación a las partes. Este derecho hace alusión a tener la oportunidad de una audiencia, contradicción y manifestación por escrito u oral, de las medidas que se están solicitando ${ }^{52}$.

\section{C) La decisión no prevista en el acuerdo de arbitraje}

La tercera causal establece que una parte podrá solicitar que se deniegue el reconocimiento y ejecución de una medida cautelar cuando se refiera a una diferencia no prevista en el acuerdo de arbitraje, o cuando excede sus términos. Cuando un tribunal arbitral dicte una medida cautelar que excede el ámbito del pacto, se está frente a un motivo particularmente común para impugnar la decisión arbitral. En este sentido, cuando el tribunal ha excedido el ámbito de competencia del pacto arbitral, la autoridad judicial deberá analizar si se podrá denegar la medida cautelar decretada, toda vez que los árbitros han actuado con base a una amplia discreción para emitir este decreto y han excedido su competencia ${ }^{53}$.

Bajo esta causal se deberá mirar que haya una congruencia entre la medida cautelar y el pacto arbitral, ya que, si aquella desborda a este, entonces carecerá de reconocimiento y ejecución la medida cautelar.

\section{D) La composición del tribunal arbitral o el procedimiento no se ajustó al acuerdo}

Este motivo de denegación de las medidas cautelares refleja lo establecido en la Ley Modelo referente a la anulación de laudos arbitrales. Las partes pueden

51 George A. Bermann, Recognition and enforcement of foreign arbitral awards: The interpretation and application of the New York Convention by National Courts (Suiza: Springer, 2017).

52 Marcela Rodríguez Mejía, “Una aproximación al régimen del arbitraje nacional del nuevo estatuto del arbitraje en Colombia, Ley 1563 de 2012", Revista de Derecho Privado (23) (2012): 367-405, https://revistas.uexternado.edu.co/index.php/derpri/article/view/3312/2962

53 Gary B. Born, "Provisional relief in international arbitration", en International commercial arbitration (La Haya: Kluwer Law International, 2014), 2424-2563. 
acordar un procedimiento o remitirse a otro ya señalado, por ende, quien solicita la denegación de la medida cautelar deberá fundamentar la petición en errores procesales cometidos en la integración del tribunal arbitral o durante el procedimiento; o alegar que bajo lo acordado por las partes el procedimiento que se dio respecto a la medida cautelar no se vio reflejado en el momento en que el tribunal arbitral decretó la medida cautelar ${ }^{54}$. Sobre este particular, la orientación general de la jurisprudencia internacional es que el vicio o procedimiento alegado debe tener incidencia en la decisión final, o dicho de otra manera, los vicios u omisiones que no sean graves no pueden tener la envergadura suficiente para producir una denegación de la medida cautelar.

\section{E) No se ha cumplido con la caución de la medida cautelar decretada}

El reconocimiento o la ejecución de la medida cautelar se podrá denegar si el tribunal arbitral ha establecido como necesaria la prestación de una caución para la medida cautelar como garantía, sin embargo, esta no se ha cumplido. El Grupo de Trabajo estableció que una autoridad judicial puede negarse a reconocer una medida cautelar si no se ha prestado la caución por el solicitante, independiente de si la decisión se tomó en forma de orden o laudo u cualquier otra forma ${ }^{55}$.

\section{F) La medida haya sido revocada o suspendida}

La sexta causal de denegación hace alusión a que la medida cautelar haya sido revocada o suspendida previamente por el tribunal arbitral, o cuando la autoridad judicial estando facultada para ello decidió revocar o suspenderla. Por ende, se podrá denegar una medida cautelar toda vez que no tendría sentido reconocerla si previamente había sido suspendida o revocada ${ }^{56}$.

La tendencia general es que no se conceda el reconocimiento o ejecución de un laudo arbitral cuando ha sido anulado en el país de la sede. Sin embargo, hay que tener en cuenta que Francia acepta el reconocimiento y ejecución de laudos anulados en la sede, con base en dos criterios: el primero, que el arbitraje internacional

54 Marcela Rodríguez Mejía, “Una aproximación al régimen del arbitraje nacional del nuevo Estatuto del Arbitraje en Colombia, Ley 1563 de 2012", Revista de Derecho Privado (23) (2012): 367-405, https://revistas.uexternado.edu.co/index.php/derpri/article/view/3312/2962 commercial arbitration: Legislative history and commentary (La Haya: Kluwer Law International, 2014), 1159-1237. 
no tiene sede ni arraigo en ningún país particular; y, en segundo lugar, que el artículo $V$ de la CNY permite que la ley de un país sobre reconocimiento y ejecución sea más benévola o laxa que la propia CNY.

Solamente para ilustrar la controversia que hay sobre el punto, traemos el caso Chromalloy Aeroservices v. República Árabe de Egipto, una disputa que surgió entre Chromalloy Aeroservices como empresa estadounidense y Egipto ante la resolución de un contrato de suministro de Chromalloy a la fuerza aérea de Egipto. Chromalloy inició un arbitraje y obtuvo laudo a su favor el cual intentó hacer cumplir en Estados Unidos. Más adelante, el Tribunal de Apelación de Egipto anuló el laudo ante la solicitud de Egipto. El Tribunal de Distrito de Estados Unidos para el Distrito de Columbia reconoció el laudo dictado en Egipto e indicó que, conforme a la CNY, un estado contratante "puede" negarse a reconocer y ejecutar un laudo; así pues, ante la decisión de anulación del laudo en el país de origen, permitiría pero no exigiría, el reconocimiento y ejecución conforme a la CNY ${ }^{57}$.

\section{G) El objeto no es susceptible de arbitraje}

Esta excepción, que puede ser decretada de oficio por la autoridad judicial, hace alusión a que el objeto sometido a arbitraje no puede ser resuelto mediante arbitraje de conformidad con la ley del país de la aplicación de la medida. La medida cautelar en un arbitraje con un reclamo no arbitrable bajo el supuesto de arbitrabilidad objetiva o subjetiva, no puede ser aplicada, por ende, se puede solicitar su denegación ${ }^{58}$.

La arbitrabilidad objetiva hace alusión a la arbitrabilidad ratione materiae en la cual la materia misma no puede ser sometida a arbitraje; mientras que la arbitrabilidad subjetiva, la arbitrabilidad ratione personae, hace alusión a que un sujeto de derecho como persona no pueda someterse a deferir esa diferencia a arbitraje.

Este artículo de denegación de la medida cautelar por la arbitrabilidad objetiva y subjetiva fue muy discutido por el Grupo de Trabajo como causal para denegar la ejecución de la medida cautelar, toda vez que el tribunal no puede tener toda la información suficiente en el momento de la ejecución de la medida cautelar, sin embargo, prevaleció que la arbitrabilidad debía ser una causal clara como motivo de denegación porque cuando el tema de la controversia es claro respecto

57 Chromalloy Aeroservices v. The Arab Republic of Egypt, 939 F. Supp. 907 (D.D.C. 1996).

58 Gary B. Born, "Validity of international arbitration awards", en International commercial arbitration: Commentary and materials (Ardsley: Transnational Publishers; La Haya, Países Bajos: Kluwer Law International) 779-880. 
a la arbitrabilidad según la ley del Estado de la ejecución, sería incoherente que la autoridad judicial que busca ejecutar haga cumplir una medida cautelar que viole la arbitrabilidad objetiva ${ }^{59}$.

\section{H) Orden público internacional}

El orden público internacional es uno de los criterios por los cuales se puede denegar de oficio la ejecución de las medidas cautelares. En este sentido, si la parte solicita la ejecución de la medida cautelar en Colombia, deberá tener en cuenta que no puede ir en contra del orden público internacional colombiano.

Es importante distinguir el orden público internacional y el interno, teniendo en cuenta que son conceptos diferentes. Para comenzar, toda norma de orden público internacional es de orden público en el derecho interno, pero no toda norma de orden público en el derecho interno es de orden público en el derecho internacional. El primero debe ser visto desde la perspectiva de los más importantes principios y valores del sistema jurídico interno; mientras que el segundo incluye las normas que también son imperativas, pero no tienen la trascendencia o la importancia de los principios, valores y normas del orden público internacional.

Entonces, tanto el orden público internacional como el orden público interno son vistos desde el derecho interno, de hecho cada país tiene una consideración particular sobre su orden público interno y su orden público internacional, ya que lo que cambia es el grado en el que se observa el orden público en específico. Los parámetros del orden público internacional son más importantes que los parámetros del derecho interno.

La Corte Suprema de Justicia de Colombia ha establecido que el concepto de orden público internacional denota valores esenciales de un Estado, sin que puedan ser susceptibles de negociación a nivel internacional, vinculados a nociones mínimas de justicia y morales porque son valores del foro o propios de él; mientras que el nacional incluye todos los principios y reglas mínimas de funcionamiento de la sociedad ${ }^{60}$.

Ahora bien, los tribunales de Nueva York han interpretado el orden público internacional de manera muy restringida en la cual se podría denegar la medida cautelar, cuando se vea que esta viola las nociones más elementales de moralidad mercial arbitration: Legislative history and commentary (La Haya: Kluwer Law International, 2014). 
y justicia. Además, al hablar de una violación del orden público se debe entender desde la perspectiva internacional y no puramente interna ${ }^{61}$. Según Margaret Moses, el orden público internacional es visto desde el lente de las leyes o estándares de un Estado para analizar un laudo extranjero ${ }^{62}$.

El orden público internacional puede considerarse un subconjunto del orden público interno, ya que se valora de manera más restringida e incluye solo las normas más fundamentales de ese orden público interno de un Estado. Este orden público internacional se debe mirar también a partir de las fuentes internacionales.

Por ende, el orden público internacional no es el mismo que el interno, ni tampoco se puede concluir que el orden público interno de todos los países es igual entre ellos, aunque sí hay preceptos similares. Dentro de los conceptos de orden público interno se puede entender que se encuentran la moral y de la justicia como principios básicos. Así pues, el orden público interno se deriva de reglas y valores que son de gran importancia y fundamentales, por lo cual, una violación al orden público interno implicaría una violación a la justicia de ese Estado ${ }^{63}$.

En suma, la diferencia entre orden público interno e internacional es de grado y no de naturaleza e implica una valoración subjetiva de la autoridad judicial; con todo, uno y otro pertenecen a cada Estado.

\section{Conclusión}

Esta Guía de medidas cautelares quiere que el lector entienda que el objetivo de la medida cautelar, tanto en la Ley Modelo como en la Ley 1563 del 2012, es que los tribunales arbitrales decreten las medidas para mantener o restablecer el statu quo, prevenir que se genere un obstáculo para el cumplimiento del laudo, preservar la prueba y los bienes en relación con el laudo final e impedir un daño presente $o$ inminente en el procedimiento arbitral.

Andreas A. Frischkencht, Yasmine Lahlou y Gretta L. Walters, "Substantive barriers to recognition and enforcement of foreign awards under article V (2) of New York and Panama Conventions", en Enforcement of foreign arbitral awards and judgments in New York (La Haya: Kluwer Law International, 2018), 164.

62 Margaret Moses, "Public policy under the New York Convention: National, international, and transnational", en 60 years of the New York Convention: Key issues and future challenges, editado por Katia Fach Gómez y Ana M. López-Rodríguez (Países Bajos: Kluwer Law International, 2019), 169. 
En el arbitraje es importante que sea el tribunal arbitral el que decrete la medida cautelar, teniendo en cuenta que es quien está en mejor posición y quien conoce del procedimiento arbitral. Sin embargo, en aquellas circunstancias en las cuales el tribunal no pueda ordenar esta medida cautelar, se podrá acudir a la autoridad judicial, en la que su intervención deberá ser de carácter excepcional y residual. De la misma manera, es relevante tener en cuenta que también se podrá acudir en estas circunstancias a la figura del árbitro de emergencia, quien podrá intervenir antes de la conformación del tribunal arbitral para que decrete una medida cautelar de carácter urgente.

En el caso colombiano, no se estipula nada acerca de la figura del árbitro de emergencia en las instituciones arbitrales, sus reglamentos ni la Ley 1563 del 2012. Por lo tanto, debería haber una introducción en este ordenamiento acerca de esta figura, lo cual supondría una ayuda en el arbitraje y generaría más integración en el arbitraje, al igual que evitaría que las partes tengan que acudir al juez antes de la constitución del tribunal arbitral. Con todo, se estima que, ante una ausencia de norma legal, las partes puedan acudir al árbitro de emergencia.

Tras un análisis realizado durante toda la Guía de medidas cautelares, se pudo dejar en evidencia que la tendencia en los diferentes casos analizados de la jurisprudencia internacional es que los tribunales arbitrales suelen decretar medidas cautelares en el arbitraje para garantizar el laudo futuro, teniendo en cuenta que son ellos quienes están en mejor posición de decretar estas medidas cautelares. También, en muchas ocasiones los tribunales arbitrales no tienen la facultad y carecen de imperio para decretar las medidas cautelares (como cuando se trata de las órdenes de embargo o momentos previos a la constitución del tribunal arbitral), razón por la cual se acude a la autoridad judicial como mecanismo subsidiario y residual para que colabore con el decreto y ejecución de la medida solicitada. Así mismo, muchos países han implementado la figura del árbitro de emergencia para que decrete medidas cautelares, teniendo en cuenta que las partes quisieron acudir al arbitraje para someter su controversia evitar recurrir a la autoridad judicial para ello.

En el caso colombiano existe un vacío respecto a las medidas cautelares anticipadas, toda vez que la Ley 1563 del 2012 solo hace énfasis a la situación en que el tribunal arbitral ya se ha integrado y constituido; no obstante, en caso de que no haya conformación del tribunal arbitral, la ley expresamente no señala qué se debe hacer, a pesar de señalar la figura la cooperación entre el juez y el árbitro.

Otras medidas muy comunes en el plano mundial pero no en el colombiano son las injunctions, en las que el árbitro puede decretar retener los activos del 
demandado que es contumaz como medida de garantía para hacerlo comparecer al juicio, al igual que el juez le ordene a la parte que no se insolvente en el extranjero para que no haga inútil el laudo arbitral o que no inicie un proceso judicialmente idéntico entre las mismas partes en el extranjero. Por otro lado, las ASI como órdenes en donde se ordena a una parte abstenerse de presentar una demanda ante la autoridad judicial de otro Estado, teniendo en cuenta que deben seguir lo establecido en el acuerdo arbitral. Ahora bien, no es claro si las injunctions y las ASI son medidas cautelares, dado que su definición no es la misma que establece la Ley 1563 del 2012 para las medidas cautelares y su objetivo puede ser considerado diferente.

De lege ferenda, el futuro del arbitraje para hacerlo completo requerirá que el árbitro se equipare verdaderamente al juez en el decreto de medidas cautelares.

\section{Referencias}

Allianz SpA and Generali Assicurazioni Generali SpA v. West Tankers Inc., Case C 185/07 Court of Justice of the European Communities (2009).

Alnaber, Rania. "Emergency arbitration: Mere innovation or vast improvement". Oxford University Press, vol. 35, Issue 4, (2019): 441-472.

American Arbitration Association. "Commercial arbitration rules and mediation procedures", 2013. www.adr.org

Bermann, George A. "Recognition and enforcement of foreign arbitral awards: The interpretation and application of the New York Convention by National Courts". Suiza: Springer, 2017.

Berger, Klaus Peter. Private dispute resolution in international business: Negotiation, mediation, arbitration. Oxford: Kluwer Law International, 2015.

Blumenthal v. Merrill Lynch, 910 F.2d 1049 (2d Cir. 1990).

Binder, Peter. International commercial arbitration and mediation in Uncitral model law jurisdictions. Países Bajos: Kluwer Law International, 2019.

Born, Gary B. "Provisional measures in international arbitration". En International arbitration: Law and practice. Países Bajos: Kluwer Law International, 2015.

-. Recognition and enforcement of international arbitral awards. En International commercial arbitration. Londres: Kluwer Law International, 2014. 
-. Validity of international arbitration awards. En International commercial arbitration: Commentary and materials. Ardsley: Transnational Publishers; La Haya, Países Bajos: Kluwer Law International.

Cavalieros, Philippe y Janet Kim. "Emergency arbitrators versus the courts: From concurrent jurisdiction to practical considerations". Journal of International Arbitration 35, n. ${ }^{\circ} 3$ (2018): 275-306.

Cetelem S.A. v. Roust Holdings Limited, Civ 618 EWCA, 2005.

Chinmax Medical Systems Inc v. Alere San Diego, 10 CV 2467 WQH (NLS), 2010.

Chromalloy Aeroservices v. The Arab Republic of Egypt, 939 F. Supp. 907 (D.D.C. 1996)

Coal India Limited v. Canadian Commercial Corporation, 172 High Court of Judicature at Calcutta (2002).

Convención sobre el Reconocimiento y la Ejecución de las Sentencias Arbitrales Extranjeras, 1958, Nueva York, 10 de junio de 1958.

Company A and Others v. Company B and Others, 3575 HKCU (2018).

Corte Suprema de Justicia, M. P. Aroldo Wilson Quiroz Monsalvo. SC99092017. Radicación n. ${ }^{\circ}$ 11001-02-03-000-2014-01927-00. Bogotá, D.C., once (11) de julio de dos mil diecisiete (2017).

-. M. P. Aroldo Wilson Quiroz Monsalvo. SC001-2019. Radicación n. ${ }^{\circ}$ 11001-02-03-000-2016-03020-00. Bogotá, D.C., quince (15) de enero de dos mil diecinueve (2019).

Ebb, Lawrence F. "Flight of assets from the jurisdiction 'in the twinkling of a telex': Pre-and post-award conservatory relief in international commercial arbitrations". Journal of International Arbitration, n. 7 (1), (1990).

Frischkencht, Andreas A., Yasmine Lahlou y Gretta L. Walters. "Substantive barriers to recognition and enforcement of foreign awards under article V (2) of New York and Panama Conventions", en Enforcement of foreign arbitral awards and judgments in New York. La Haya: Kluwer Law International, 2018.

Fouchard, Philippe, Emmanuel Gaillard y Berthold Goldman. "Provisional and conservatory measures in the course of the arbitration proceedings", en International commercial arbitration, editado por Emmanuel Gaillard y John Savage, 711. La Haya; Boston; Londres: Kluwer Law International, 1999.

Gaillard, Emmanuel y Diego P. Fernández. Cuestiones claves del arbitraje internacional. Bogotá: Universidad del Rosario, 2013. 
Gaillard, Emmanuel. "Reflections on the use of anti-suit injunctions in international arbitration", en Pervasive problems in international arbitration, editores Loukas A. Mistelis y Julian David Matthew Lew. Países Bajos: Kluwer Law International, 2006.

Graham, Luis Enrique. "Interim measures: Ongoing regulation and practices (A view from the Uncitral arbitration regime)". En 50 years of the New York Convention: ICCA International Arbitration Conference, ICCA Congress Series, editado por Albert Jan Van den Berg. Países Bajos: Kluwer Law International, 2009.

Holtzmann, Howard M. y Joseph E. Neuhaus. A guide to the Uncitral model law on international commercial arbitration: Legislative history and commentary. La Haya; Boston; Londres: Kluwer Law International, 2014 International Chamber of Commerce (ICC). Rules of arbitration, 2017. —. Pre-arbitral referee rules, 1990.

Ku-Ring-Gai Council v. Ichor Constructions Pty Ltd, 110112 NSWCA (2019). Ley 1563 del 2012, 12 de julio del 2012. Diario Oficial 48.489.

Ley 1563 del 2012. Gaceta 270 del 2012 del Congreso de la República. Comisión Primera Constitucional. Acta 33 del 2012. Bogotá, D. C., jueves, 24 de mayo del 2012.

Ley 1563 del 2012. Gaceta 321 del 2012 del Congreso de la República. Comisión Primera Constitucional, Segundo debate Plenaria. Bogotá, D. C., miércoles, 6 de junio del 2012.

Ley Modelo de la Convención de la Comisión de las Naciones Unidas para el Derecho Mercantil Internacional, Resolución 40/72, 11 de diciembre de 1985, Resolución 61/33, 4 de diciembre del 2006.

Mareva Compania Naviera SA v. International Bulkcarriers SA', 1 All ER 213 Court of Appeal, Civil Division (1980).

Matthew Lew, Julian David. "Control of jurisdiction by injunctions issued by National Courts". En International arbitration 2006: Back to basics, editado por Albert Jan van den Berg. Montreal: Kluwer Law International, 2007.

Matthew Lew, Julian David, Loukas A. Mistelis y Stefan M Kröll. "Interim and conservatory measures". En Comparative international commercial arbitration. La Haya, Países Bajos: Kluwer Law International, 2003.

Moses, Margaret. "Public policy under the New York Convention: National, international, and transnational". En 60 years of the New York Convention: Key issues and future challenges, editado por Katia Fach Gómez y Ana M. López-Rodríguez. Países Bajos: Kluwer Law International, 2019. 
-. "Public policy: National, international and transnational". Kluwer Arbitration (blog), 12 de noviembre del 2018. http://arbitrationblog. kluwerarbitration.com/2018/11/12/public-policy-national-internatio nal-and-transnational/

NCC International AB v. Alliance Concrete Singapore Pte Ltd, 2 SLR(R) 565 (2008).

Pombo, Fernando. Arbitration and anti suit injunctions in the case law of the European Court of Justice. España: La Ley 2010, 2010.

Reyes-Sinisterra, Cindy Charlotte. "Las medidas cautelares anticipatorias e innominadas en el proceso arbitral en colombia". Revista Vniversitas n. 132 (2016): 390-421, https://doi.org/10.11144/Javeriana.vj132.mcai

Reglamento General del Centro de Conciliación, Arbitraje y Amigable Composición de la Cámara de Comercio de Cali, 27 de agosto del 2020. Reglamento Centro de Arbitraje y Conciliación, Cámara de Comercio de Bogotá, 28 de septiembre del 2019.

Rich, March. El arbitraje y el Reglamento de Bruselas I Refundido, las Anti-Suit Injunction, y ahora El Brexit". Osborne Clarke LLP (blog), acceso 5 de diciembre del 2010, https://www.osborneclarke.com/wp-content/ uploads/2016/11/El-Arbitraje-y-el-Reglamente-Bruselas-I-Refundi do-las-Anti-Suit-Injunction-y-ahora...-el-Brexit.pdf

Rodríguez Mejía, Marcela. "Ejecución de la decisión cautelar". En Medidas cautelares en el proceso arbitral, 345-433. Bogotá: Universidad Externado de Colombia, 2013.

-. "Una aproximación al régimen del arbitraje nacional del nuevo estatuto del arbitraje en Colombia, Ley 1563 del 2012". Revista de Derecho Privado (23) (2012): 367-405, https://revistas.uexternado.edu.co/in dex.php/derpri/article/view/3312/2962

Sonera Holding B.V. v. Cukurova Holding A.S., Partial Award. ICC Case No. 13856 (2007).

SVM Holding, S.A. v. Nexus Maritime Service GMBH, 4:15-cv-02581 US District Court for the Southern District of Texas (2015).

Shengchang, Wang, y Cao Lijun. The Role of National Courts and Lex Fori in International Commercial Arbitration. En Pervasive Problems in International Arbitration. Londres: Kluwer Law International, 2006.

Yahoo! Inc. v. Microsoft Corporation, 13 CV 7237 US SDNY (2013).

Yesilirmak, Ali. Provisional measures in international commercial arbitration. Kluwer Law International, 2005. 